\title{
Kidney Transplantation From a Donor With Sickle Cell Disease
}

\author{
A. Rossidis ${ }^{1}$, M. A. Lim ${ }^{2}$, M. Palmer ${ }^{3}$, M. H. Levine ${ }^{1}$, A. Naji ${ }^{1}$, R. D. Bloom ${ }^{2}$, and P. L. Abt ${ }^{1}{ }^{*}$ \\ ${ }^{1}$ Department of Surgery, The Hospital of the University of Pennsylvania, Philadelphia, PA \\ 2Division of Nephrology, Department of Medicine, The Hospital of the University of Pennsylvania, \\ Philadelphia, PA \\ ${ }^{3}$ Department of Pathology and Laboratory Medicine, The Hospital of the University of \\ Pennsylvania, Philadelphia, PA
}

\begin{abstract}
In the United States, >100 000 patients are waiting for a kidney transplant. Given the paucity of organs available for transplant, expansion of eligibility criteria for deceased donation is of substantial interest. Sickle cell disease (SCD) is viewed as a contraindication to kidney donation, perhaps because SCD substantially alters renal structure and function and thus has the potential to adversely affect multiple physiological processes of the kidney. To our knowledge, transplantation from a donor with SCD has never been described in the literature. In this paper, we report the successful transplantation of two kidneys from a 37-year-old woman with SCD who died from an intracranial hemorrhage. Nearly 4 mo after transplant, both recipients are doing well and are off dialysis. The extent to which kidneys from donors with SCD can be safely transplanted with acceptable outcomes is unknown; however, this report should provide support for the careful expansion of kidneys from donors with SCD without evidence of renal dysfunction and with normal tissue architecture on preimplantation biopsies.
\end{abstract}

\section{Introduction}

In the United States, >100 000 patients are waiting for a kidney transplant (1). Given the paucity of organs available for transplant, expansion of eligibility criteria for deceased donation is of substantial interest. Sickle cell disease (SCD) is viewed as a contraindication to kidney donation. To our knowledge, transplantation from a donor with SCD has not been reported, perhaps because SCD substantially alters renal structure and function and thus has the potential to adversely affect multiple physiological processes of the kidney. SCD has been shown, for example, to alter renal hemodynamics, to impair urinary concentrating ability and to increase the risk of both acute kidney injury and chronic kidney disease over the lifetime of affected patients (2). The underlying mechanism of such damage likely stems from the fact that stasis occurs in the renal medulla, especially within the vasa recta, resulting in hypoxia and acidosis, both of which increase the concentration of sickled

\footnotetext{
"Corresponding author: Peter L. Abt, peter.1.abt@uphs.upenn.edu.

Disclosure

The authors of this manuscript have no conflicts of interest to disclose as described by the American Journal of Transplantation.
} 
hemoglobin and promote damage to the endothelium (2). For these reasons, many physicians are likely hesitant to consider deceased donors with SCD.

\section{Case Report}

We report the transplantation of two kidneys from a 37- year-old woman (BMI 22) with SCD who died from an intracranial hemorrhage. She had a prior splenic infarction and recent inpatient admission for sickle cell crisis in the setting of upper respiratory and urinary tract infections. Aside from the history of prior urinary tract infections, there was no history of gross hematuria, proteinuria or sickle cell nephropathy, and her terminal creatinine level was $0.5 \mathrm{mg} / \mathrm{dL}$ (Kidney Donor Profile Index 60\%). Frozen-section biopsies of both kidneys were obtained and reviewed prior to transplantation. Examination of the glomeruli failed to identify global or segmental sclerosis, and there was no evidence of glomerular enlargement. No endocapillary hypercellularity or microthrombi were seen within the capillary lumens, and interstitial edema or hemorrhage was absent, with minimal interstitial fibrosis (5\%). Hemosiderin deposition was the only remarkable histologic finding and may have accounted for the brownish external hue noted on gross examination (Figure 1). The role of iron deposition in the kidney in SCD nephropathy is largely unknown, but some evidence shows that cellular iron buildup can trigger activation of the apoptotic caspase system, upregulation of reactive oxygen species and release of inflammatory mediators (3-5). Both patients were extensively counseled as to the nature of the donor disease and potential unknown implications for future allograft function. In addition, both were recipients who we felt had little opportunity to obtain a kidney transplant in the near future and had a high risk of mortality while on dialysis.

Recipient 1 was a 59-year-old woman with hypertension and end-stage renal disease (ESRD) secondary to polycystic kidney disease who had renal replacement through peritoneal dialysis for 1 year. She had no potential living donors and wanted to be free from dialysis. Her postoperative course was notable for delayed graft function requiring 3 days of hemodialysis. Nearly 4 mo after transplant, her creatinine level was $2.1 \mathrm{mg} / \mathrm{dL}$, and she had trace protein on urinalysis. Recipient 2 was a 67-year-old man with hypertension, diabetes, idiopathic cardiomyopathy, and ESRD resulting from nonrecovery of acute kidney injury complicating a prior orthotopic heart transplant 5 years earlier who had been hemodialysisdependent since the transplant. He also required 3 days of hemodialysis, and aside from a urinary tract infection and Clostridium difficile colitis, his postoperative course was unremarkable. His most recent creatinine level was $1.5 \mathrm{mg} / \mathrm{dL}$, and he had had no proteinuria. Both recipients had 0\% panel reactive antibody and received three doses of thymoglobulin for induction. Maintenance immunosuppression regimens were identical and consisted of mycophenolate mofetil, tacrolimus and prednisone.

\section{Discussion}

Although there have been reports of kidney transplantation from donors with sickle cell trait (6), this is the first time, to our knowledge, that kidneys from a donor with SCD have been used for transplantation. In the United States, it is estimated that $70000-100000$ people have SCD (7). The mortality rate for patients with SCD is reported at 2.5 per 100000 in the 
black population, with a mean age of death in the fourth decade (8). Perhaps surprisingly, it is estimated that only $\approx 10 \%$ of SCD patients have chronic renal failure at the time of death (9). The extent to which kidneys from donors with SCD can be safely transplanted with acceptable outcomes is unknown; however, this report should provide support for the careful expansion of kidneys from donors with SCD without evidence of renal dysfunction and with normal tissue architecture on preimplantation biopsies. Predictors of the development of renal disease in SCD patients, such as age, duration of disease, frequency of crises or hospitalizations, hypertension, proteinuria, and increasingly severe anemia, should be considered prior to biopsy $(10,11)$. The sickle cell status of the donor should be communicated to the recipient, and perhaps initially, kidneys from patients with SCD may be reserved for recipients with a higher risk of waitlist mortality and those with shorter expected posttransplant survival until we learn more about the natural history of these transplanted organs.

\section{Abbreviations \\ ESRD end-stage renal disease \\ SCD $\quad$ sickle cell disease}

\section{References}

1. U.S. Department of Health \& Human Services [Internet]. Richmond: Organ Procurement and Transplantation Network; 2016. [cited 2016 Jun 19]. Available from: https:// optn.transplant.hrsa.gov/data/

2. Nath KA, Hebbel RP. Sickle cell disease: Renal manifestations and mechanisms. Nat Rev Nephrol. 2015; 11:161-171. [PubMed: 25668001]

3. Gordeuk VR, Bacon BR, Brittenham GM. Iron overload: Causes and consequences. Annu Rev Nutr. 1987; 7:485-508. [PubMed: 3300744]

4. Tracz MJ, Alam J, Nath KA. Physiology and pathophysiology of heme: Implications for kidney disease. J Am Soc Nephrol. 2007; 18:414-420. [PubMed: 17229906]

5. Zhou XJ, Laszik Z, Wang XQ, Silva FG, Vaziri ND. Association of renal injury with increased oxygen free radical activity and altered nitric oxide metabolism in chronic experimental hemosiderosis. Lab Invest. 2000; 80:1905-1914. [PubMed: 11140702]

6. Rehman SU, Al-Amoudi A, Kelta M, Awad A, Bridges K, Al-Ghamdi SM. Kidney transplant from sickle cell trait donor to sickle cell trait recipient. Exp Clin Transplant. 2007; 5:698-700. [PubMed: 18194125]

7. Sickle Cell Disease Association of America [Internet]. Baltimore: About SCD \& SCT; 2016. [cited 2016 Aug 17]. Available from: http://www.sicklecelldisease.org/about/sickle-cell-101/

8. Lanzkron S, Carroll CP, Haywood C. Mortality rates and age at death from sickle cell disease: U.S. 1979-2005. Public Health Rep. 2013; 128:110-116. [PubMed: 23450875]

9. Platt O, Brambilla D, Rosse W, et al. Mortality is sickle cell disease-life expectancy and risk factors of early death. N Engl J Med. 1994; 330:1639-1644. [PubMed: 7993409]

10. Arogundade FA, Sanusi AA, Hassan MO, Salawu L, Durosinmi MA, Akinsola A. An appraisal of kidney dysfunction and its risk factors in patients with sickle cell disease. Nephron Clin Pract. 2011; 118:c225-c231.

11. Powara DR, Elliott-Mills DD, Chan L, et al. Chronic renal failure in sickle cell disease: Risk factors, clinical course, and mortality. Ann Intern Med. 1991; 115:614-620. [PubMed: 1892333] 


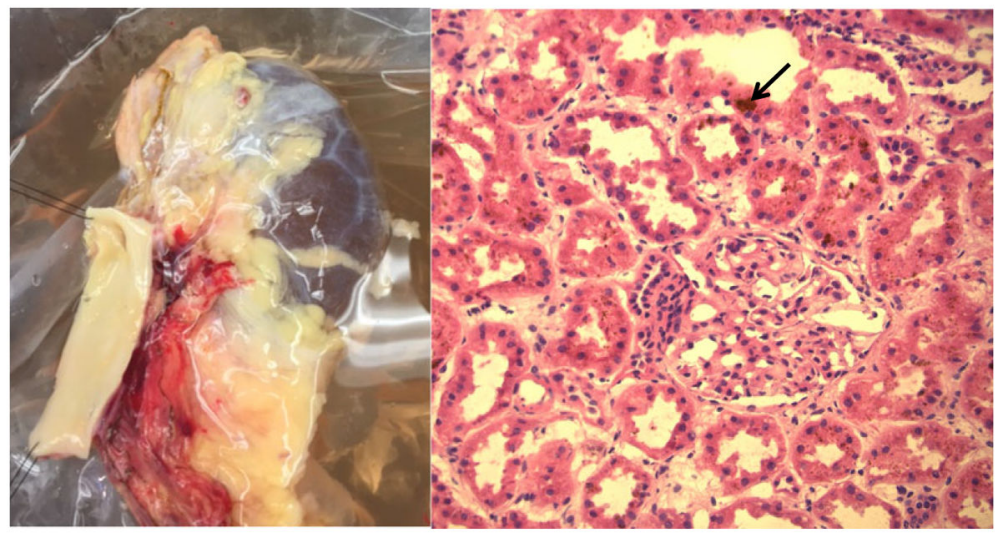

Figure 1. Gross and histological examination of the donor kidneys

The only abnormality seen is the hemosiderin (brown granules, arrow) within some of the tubular epithelial cells, which is typical for a patient with sickle cell disease. 